\title{
Una visión global de la Biotecnología en Colombia.
}

\section{An overview of Biotechnology in Colombia. \\ Dagoberto Castro - Restrepo}

La estratégica localización geográfica de Colombia le ha permitido contar con la segunda mayor biodiversidad y además ser uno de los 12 países megadiversos en el mundo; sin embargo, como se menciona en el V informe de Biodiversidad en Colombia es igualmente complejo y frágil aún falta tomar mayor conciencia sobre la importancia de la biodiversidad y los servicios económicos como parte del desarrollo sostenible. ${ }^{1}$ En tal sentido, la biotecnología se presenta como una oportunidad para afrontar este reto, para lo cual existen esfuerzos Nacionales liderados por el Departamento administrativo de Ciencia, Tecnología e Innovación de Colombia - COLCIENCIAS- como son el Programa Nacional de Biotecnología con sus líneas de fortalecimiento de la industria biotecnológica, desarrollo y producción de biocombustibles y el conocimiento, protección y aprovechamiento sostenible de la biodiversidad. ${ }^{2}$

Respecto a la formación del talento humano en Biotecnología, en Colombia se tienen dos programas de pregrado, ocho especializaciones, once maestrías y tres programas de doctorado, que considerando las oportunidades para el país son todavía deficitarios. En este mismo sentido, se registran 114 grupos de investigación reconocidos por Colciencias en temas agropecuarios, salud, farmacia, ambiental e industrial.

Como oportunidad para el fortalecimiento de la biotecnología del país, el Estado Colombiano ha identificado sectores que ha denominado de clase mundial, entre los que se destacan la Chocolatería y confitería, carne bovina, hortofrutícola, acuícola, lácteo, palma, aceites, grasas y sus biocombustibles así como los productos para cosmética y aseo; ${ }^{3}$ por lo tanto, para que estos sectores sean competitivos se debe tener la convergencia del estado, las empresas privadas, las Universidades y Centros de desarrollo tecnológico

Recientemente COLCIENCIAS ha promovido el "Proyecto Colombia BIO" cuyo principal objetivo es propiciar condiciones para conocer, valorar, conservar y aprovechar sosteniblemente la biodiversidad del país, contribuyendo a un desarrollo sostenible y socialmente inclusivo, cuyos componentes tienen como meta articular una gran cadena de valor de la biodiversidad y crear condiciones para ser competitivos. ${ }^{4}$

Por lo tanto, teniendo como referencia la riqueza en recursos de la biodiversidad, la oferta de formación académica, el talento humano a través de los grupos de investigación, es una fortaleza que debe ser capitalizada en forma articulada con el estado como ente gestor y la empresa privada como inversionista, teniendo en cuenta que el país cuenta con 157 compañías biotecnológicas con aplicaciones en los sectores de cosméticos, medicina, industria, agropecuario, alimentos, ambiente y energía. En este sentido, para generar cooperación equitativa y de confianza las Universidades tenemos la tarea de establecer nuestros propios modelos de negocios, de gestión y de operación en el marco de la propiedad intelectual, en un ámbito de Ética y Responsabilidad Social Universitaria.

En este sentido, la Universidad Católica de Oriente la Unidad de Biotecnología Vegetal ha contribuido al desarrollo de la biotecnología en el país por más de 20 años, con procesos de reproducción clonal masiva de musáceas como bananos del grupo "Cavendish"
DOI. 10.21931/RB/2016.01.04.1

donde se han producido más de 10 millones de plantas con destino a mercados nacionales e internacionales. En especies forestales se han realizado investigaciones para la revigorización, reproducción clonal y el uso de marcadores moleculares para la selección y propagación de teca, abarco, eucaliptos y pinos. Así mismo en frutales se han establecido protocolos para la micropropagación de ecotipos de mora de castilla, agraz (mortiño), piña y el desarrollo de patrones tolerantes a estrés biótico y abiótico en especies de tomate de árbol, lulo y aguacate. En el cultivo de la papa se han desarrollado métodos moleculares para la detección de virus, viroides y producción de microtubérculos in vitro.

En los últimos años se han desarrollado investigaciones en alianza con el sector farmacéutico para la producción de metabolitos secundarios como polifenoles en mortiño (Vaccimium meridionale), fitosteroles en ñame, zanahoria y yacón; y eritadenina a partir del hongo shiitake (Lentinula edodes); así como un proyecto de investigación en Amaryllidaceas, en cooperación con 11 países, para la búsqueda de principios activos para el tratamiento de la enfermedad de Alzheimer y otras enfermedades neurodegenerativas.

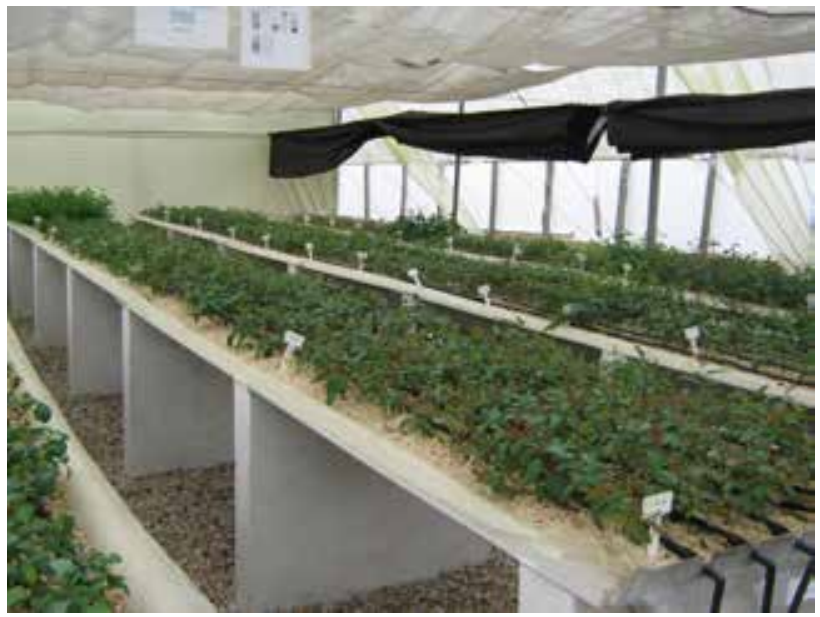

Mini jardín clonal hidropónico para la propagación masiva de plantas de abarco, teca y eucaliptos reproducidas in vitro.

\section{Referencias biobliográficas}

1. http://www.co.undp.org/content/dam/colombia/docs/MedioAmbiente/undp-co-informebiodiversidad-2014.pdf

2. http://legadoweb.colciencias.gov.co/programa_estrategia/programa-nacional-de-biotecnolog-0

3. https://www.ptp.com.co/portal/default.aspx. de Martel C, Ferlay J, Franceschi S, et al. Global burden of cancers attributable to infections in 2008: a review and synthetic analysis. The Lancet Oncology 2012;13: 607-615

4. http://www.colciencias.gov.co/content/colombia-bio.

Dr. Dagoberto Castro - Restrepo. PhD Líder Grupo de investigación Unidad de Biotecnología. Universidad Católica de Oriente Autor de correspondencia: investigacion.dir@uco.edu.co 